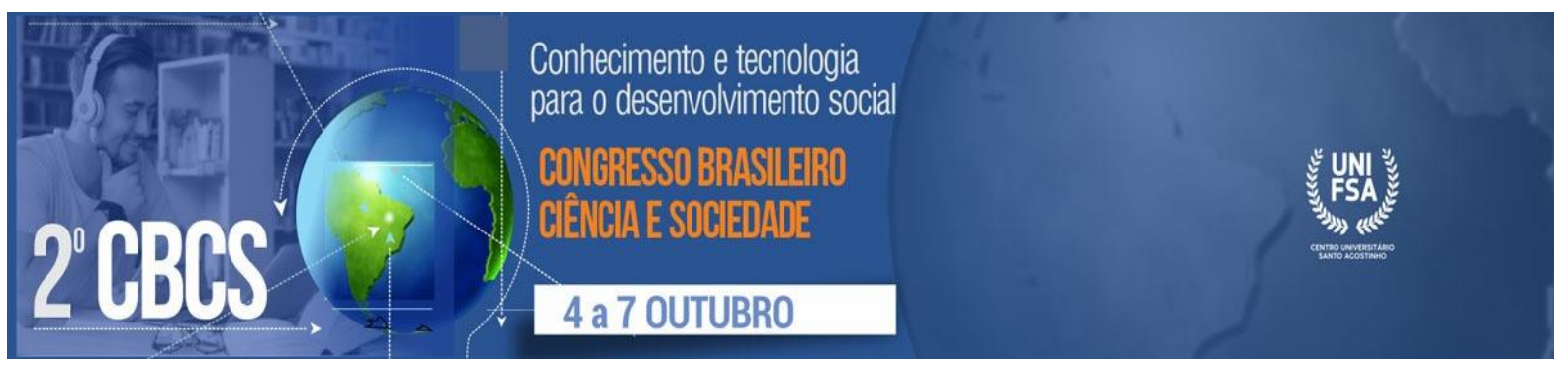

\title{
ENSINO REMOTO: IMPLICAÇÕES E POSSIBILIDADES DE APRENDIZAGEM NO CONTEXTO DA PANDEMIA POR COVID-19 ${ }^{1}$
}

\author{
Juliana Priscila Santos de Sampaio (UNIFSA) ${ }^{2}$
}

\section{RESUMO}

A pesquisa possui o objetivo geral de compreender as implicações e possibilidades do ensino remoto no contexto da pandemia por COVID-19. No Brasil, com a nova realidade de ensino remoto, alunos e professores aprenderam a manusear diferentes sistemas de vídeo conferencias ou plataformas digitais para as práticas de transmissão de aulas. A produção da pesquisa se constitui em uma revisão sistemática da literatura, pois ela possibilita critérios de rigor científico para que os métodos de pesquisa sejam eficazes e resultem na produção de conhecimentos qualificados em detrimento do problema de pesquisa. Ressalta-se, que são necessárias intervenções e estratégias coletivas para que todos os indivíduos participem de modo ativo no processo de ensino remoto e a aprendizagem digital se torne democrática e de qualidade.

Palavras-Chave: educação. Aprendizado. Internet. Tecnologia.

\section{ABSTRACT}

The research has the general objective of recovery as freedom and remote learning possibilities in the context of the COVID-19 pandemic. In Brazil, with the new reality of remote teaching, students and teachers have learned to handle different video conferencing systems or digital platforms for classroom transmission practices. The research production consists of a systematic literature review, as it enables criteria of scientific rigor so that research methods are effective and result in the production of knowledge to the detriment of the research problem. It is noteworthy that collectives are necessary and necessary so that everyone who has to actively participate in the remote teaching process and digital learning becomes democratic and of quality.

Keywords: education. Learning. Internet. Technology.

\footnotetext{
${ }^{1}$ Trabalho apresentado no 2 o Congresso Brasileiro Ciência e Sociedade (CBCS 2021), promovido pelo Centro Universitário Santo Agostinho, de 04 a 07 de outubro de 2021, em Teresina-PI.

2 Técnica em Manutenção e Suporte em Informática. Graduanda de Psicologia, no Centro Universitário Santo Agostinho (UNIFSA), E-mail: julianapriscilapsicologa@gmail.com.
} 


\section{INTRODUÇÃO}

No Brasil, destaca-se a importância do ensino online, que expande a educação no decorrer dos anos e possibilitam novas práticas e propostas, assim como reflexões sobre os processos de ensino-aprendizagem com o auxílio da tecnologia (VERASZTO et al, 2009).

No entanto, com a expansão do vírus (SARS-CoV-2) foram acionadas medidas emergenciais por meio do ensino remoto ou à distância, acelerando o processo de educação digital, para que durante a pandemia da COVID-19 as práticas em rede virtual substituam a ausência de aulas presenciais. (MOREIRA, HENRIQUES, BARROS, 2020).

Ressalta-se, que existe diferença entre ensino remoto e a distancia, pois segundo (HODGES et al 2020), o ensino remoto surge como uma alternativa temporária para fornecer suportes e conteúdos de modo prático, rápido e confiável, pois o cenário de crise demandou mudanças temporárias, no qual evidencia-se o aprendizado online. Ademais, o aprendizado que é o produto do processo da aprendizagem se torna insuficiente quando não se aplica a prática de inovação e reflexão, nesse ínterim, as metodologias tradicionais não preparam e estimulam os alunos para lidarem com a complexidade do atual contexto do mundo (MUNCK, BORGES, 2020).

Segundo os autores Moreira; Henriques; Barros (2020, p. 352), com a nova realidade de ensino remoto no Brasil, alunos e professores aprenderam a manusear diferentes sistemas de vídeo conferencias ou plataformas digitais para as práticas de ensino e transmissão de aulas. Ademais, foram criados novos modelos de aprendizagem virtual para inclusão do novo processo que demandou adaptações, inclusive por parte dos docentes que através de suas respectivas gravações de aulas podem ser comparados a Youtubers (criadores de conteúdo para a plataforma de compartilhamento de vídeos norte-americana YouTube).

Nesse viés, o tema da pesquisa é atual e relevante para analisar os desafios que surgem através do ensino remoto, pois o Brasil não é um país democrático em relação ao acesso a aparelhos eletrônicos e serviços de Internet estáveis, tornando-se 
essencial a reflexão e discussão das variáveis que surgem para as práticas de uma aprendizagem de qualidade e educação acessível desde o ensino básico ao superior.

Conforme a importância desse tema para a presente realidade que discentes e docentes enfrentam com a educação durante a pandemia, esta pesquisa possui o objetivo geral de compreender as implicações e possibilidades do ensino remoto no contexto da pandemia por COVID-19.

\section{METODOLOGIA}

A produção da pesquisa se constitui em uma revisão sistemática da literatura, pois ela possibilita critérios de rigor científico para que os métodos de pesquisa sejam eficazes e resultem na produção de conhecimentos qualificados em detrimento do problema de pesquisa. Além de viabilizar a investigação e avaliação da qualidade dos artigos selecionados através do protocolo de pesquisa (ERCOLE, MELO, ALCOFORADO, 2014).

Na realização da amostra, em junho de 2021, utilizou-se o levantamento de pesquisas publicadas por meio de busca nas bases de dados eletrônicas: SCIELO (Scientific Eletronic Library Online), plataforma digital Google Acadêmico, periódicos CAPES e LILACS (Literatura Latino-Americana e do Caribe em Ciências da Saúde). Nesse ínterim, através do site DeCS (Descritores em Ciências da Saúde), foram utilizados os seguintes descritores: educação. Aprendizado. Internet. Tecnologia.

Infere-se que os critérios de inclusão da pesquisa foram: artigos publicados no período de março de 2020 a junho de 2021 e que estivessem relacionados ao tema proposto e ao problema de pesquisa, além de pesquisas com disponibilidade de leitura completa e gratuita. Ademais, os critérios de exclusão foram: pesquisas de leitura incompleta ou privada e fora do tema proposto pela análise de revisão sistemática.

O plano para a análise de dados consistiu em leituras minuciosas e apuração de informações úteis, no qual também foi desenvolvido um formulário para categorizar as publicações e suas características metodológicas, selecionando os seguintes dados: título, ano de publicação, autores, periódico de publicação, objetivos e resultados.

Encontrou-se o total de 16.208 artigos relacionados ao tema, deste total foram identificadas 49 produções no SCIELO, 15.600 no Google Acadêmico, 519 no CAPES e 
40 no LILACS. Dessa forma, 6.208 artigos foram eleitos após a seleção e com a utilização de filtros e busca nos resumos 208, nesse ínterim 199 artigos foram removidos por atenderem os critérios de exclusão e 9 foram incluídos no banco de dados final, sendo respectivamente: 4 artigos pelo SCIELO, 3 pelo Google Acadêmico, 1 pelo CAPES e 1 pelo LILACS.

A partir da seleção das publicações que atenderam os critérios de inclusão e exclusão foram consideradas as recomendações do Preferred Reporting Items for Systematic Reviews and Meta-Analyses (PRISMA), no qual dois pesquisadores independentes realizaram a seleção das publicações identificadas. Primeiramente avaliando as metodologias relevantes de acordo com a temática e em seguida a seleção pelos critérios pré-definidos de inclusão e exclusão.

IMAGEM 1. Fluxograma com resultado das buscas nas bases de dados. Teresina, 2021.

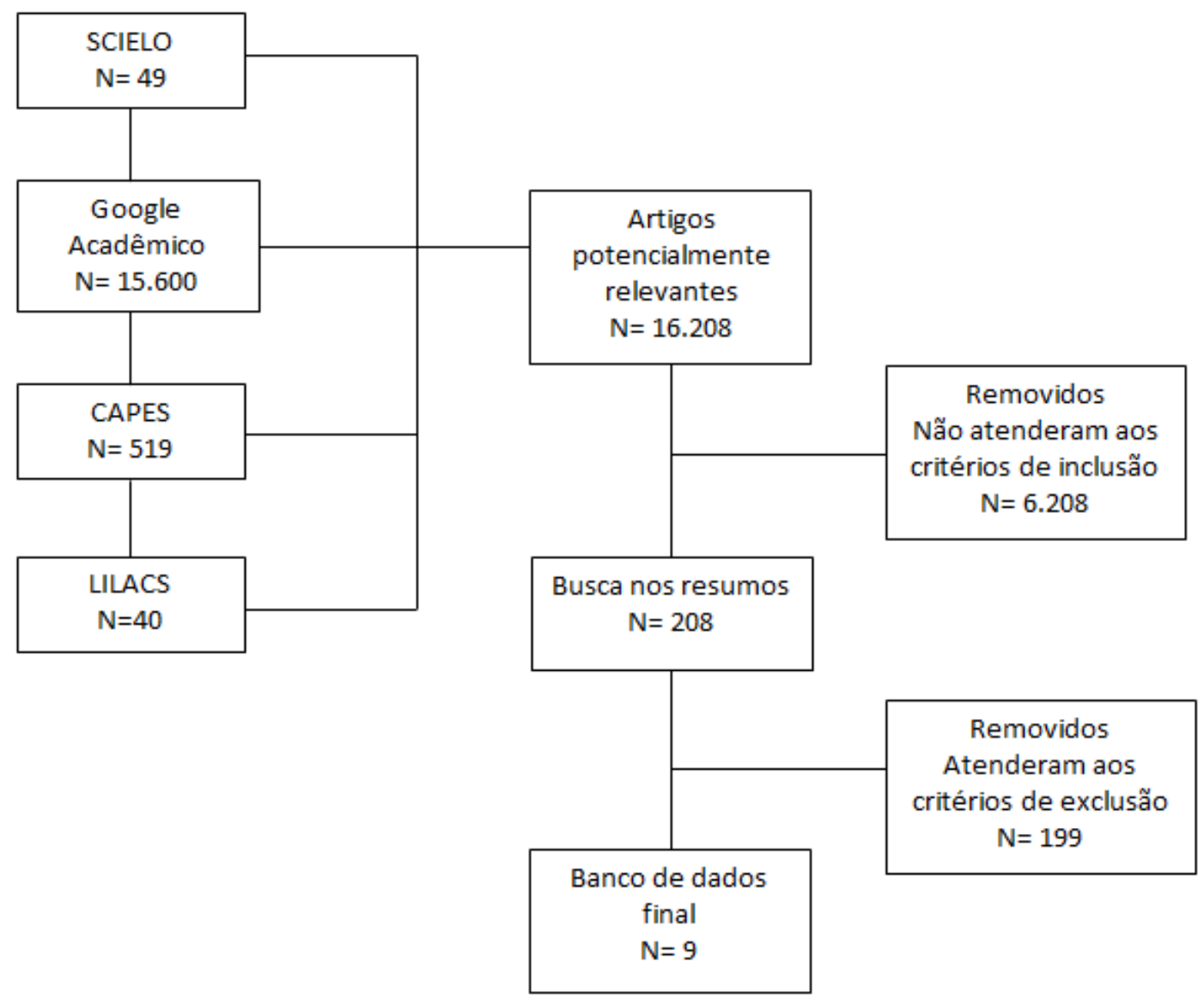

Fonte: fluxograma das etapas da revisão sistemática recomendada pelo PRISMA. 
A presente revisão sistemática foi estruturada como artigo e seguiu as regras da APA (American Psychological Association), ademais, as nove produções selecionadas seguiram os processos de: análise, apuração das principais ideias dos autores, verificação dos resultados e conclusões de cada publicação. Ressalta-se ainda que os dados coletados das pesquisas foram organizados e apresentados em tabelas através de imagens.

\section{RESULTADOS}

Nota-se que os resultados utilizaram periódicos inclusos nesta pesquisa e registrados nas bases de dados, ademais, promoveram a elaboração de reflexões com perspectivas similares ou discordantes entre os autores sobre o tema: ensino remoto: implicações e possibilidades de aprendizagem no contexto da pandemia por COVID-19. Os resultados coletados foram organizados em um quadro, que consta as principais informações dos artigos analisados, como: autores, ano, periódico, objetivos e resultados da pesquisa, respectivamente.

IMAGEM 2. Tabela de caracterização dos artigos selecionados por autores, ano, periódico, objetivos e resultados da pesquisa, respectivamente.

\begin{tabular}{|c|c|c|c|c|}
\hline $\begin{array}{l}\text { AUTORES/ } \\
\text { ANO }\end{array}$ & $\begin{array}{l}\text { TÍTULO DO } \\
\text { ARTIGO }\end{array}$ & $\begin{array}{l}\text { NOME DA } \\
\text { REVISTA }\end{array}$ & $\begin{array}{c}\text { OBJETIVOS } \\
\text { DO } \\
\text { TRABALHO }\end{array}$ & $\begin{array}{c}\text { CONCLUSÕES DA } \\
\text { PESQUISA }\end{array}$ \\
\hline $\begin{array}{c}\text { MOREIRA, } \\
\text { HENRIQUES, } \\
\text { BARROS, } 2020\end{array}$ & $\begin{array}{l}\text { Transitando de } \\
\text { um ensino } \\
\text { remoto } \\
\text { emergencial para } \\
\text { uma educação } \\
\text { digital em rede, } \\
\text { em tempos de } \\
\text { pandemia. }\end{array}$ & $\begin{array}{l}\text { Revista } \\
\text { Dialogia }\end{array}$ & $\begin{array}{l}\text { Apresentar os } \\
\text { princípios } \\
\text { básicos para o } \\
\text { design de um } \\
\text { ambiente } \\
\text { online, } \\
\text { relacionado à } \\
\text { organização, } \\
\text { seleção de } \\
\text { recursos, } \\
\text { preparação e } \\
\text { avaliação de e- } \\
\text { atividades de } \\
\text { aprendizagem. }\end{array}$ & $\begin{array}{l}\text { Explicitar os princípios } \\
\text { básicos que um professor } \\
\text { deve conhecer para o design } \\
\text { de um ambiente online e } \\
\text { propor o desenvolvimento } \\
\text { de programas deformação e } \\
\text { capacitação para todos os } \\
\text { agentes educativos. }\end{array}$ \\
\hline
\end{tabular}




\begin{tabular}{|c|c|c|c|c|}
\hline $\begin{array}{l}\text { VALENTE, } \\
\text { MORAES, } \\
\text { SANCHEZ, } \\
\text { SOUZA, } \\
\text { PACHECO, } 2020\end{array}$ & $\begin{array}{l}\text { O ensino remoto } \\
\text { frente às } \\
\text { exigências do } \\
\text { contexto de } \\
\text { pandemia: } \\
\text { Reflexões sobre } \\
\text { a prática } \\
\text { docente. }\end{array}$ & $\begin{array}{l}\text { Research, } \\
\text { Society and } \\
\text { Development }\end{array}$ & $\begin{array}{l}\text { Realizar uma } \\
\text { análise reflexiva } \\
\text { sobre a prática } \\
\text { docente no } \\
\text { ensino remoto, } \\
\text { em tempos de } \\
\text { pandemia. }\end{array}$ & $\begin{array}{l}\text { Discutir sobre as buscas } \\
\text { formas de lidar com a } \\
\text { realidade, que afeta as } \\
\text { pessoas não só no seu } \\
\text { processo de aprender a } \\
\text { aprender, mas nos aspectos } \\
\text { físicos, emocionais e sociais, } \\
\text { diante da crise mundial } \\
\text { instalada. }\end{array}$ \\
\hline $\begin{array}{l}\text { SANTANA, } \\
\text { SALES, } 2020\end{array}$ & $\begin{array}{l}\text { Aula em casa: } \\
\text { educação, } \\
\text { tecnologias } \\
\text { digitais e } \\
\text { pandemia } \\
\text { COVID-19. }\end{array}$ & $\begin{array}{l}\text { Interfaces } \\
\text { Científicas }\end{array}$ & $\begin{array}{c}\text { Conhecer e } \\
\text { discutir práticas } \\
\text { pedagógicas da } \\
\text { educação } \\
\text { formal frente } \\
\text { ao contexto } \\
\text { pandêmico } \\
\text { causado pelo } \\
\text { novo } \\
\text { coronavírus. }\end{array}$ & $\begin{array}{l}\text { As práticas em EAD sem } \\
\text { fundamentação podem } \\
\text { comprometer o percurso de } \\
\text { construção de uma cultura } \\
\text { institucional para o } \\
\text { desenvolvimento dos } \\
\text { processos formativos na } \\
\text { modalidade a distância. }\end{array}$ \\
\hline $\begin{array}{c}\text { OLIVEIRA, } \\
\text { FERNANDES, } \\
\text { ANDRADE, } \\
2020\end{array}$ & $\begin{array}{l}\text { Educação no } \\
\text { contexto da } \\
\text { pandemia da } \\
\text { Covid-19: } \\
\text { adversidades e } \\
\text { possibilidades. }\end{array}$ & $\begin{array}{l}\text { Itinerarius } \\
\text { Reflectionis }\end{array}$ & $\begin{array}{l}\text { Discutir } \\
\text { perspectivas de } \\
\text { práticas } \\
\text { educativas, por } \\
\text { meio do uso de } \\
\text { metodologias } \\
\text { ativas, para } \\
\text { aulas remotas. }\end{array}$ & $\begin{array}{l}\text { O ensino remoto favorece a } \\
\text { adoção de novas práticas } \\
\text { pedagógicas que podem } \\
\text { contribuir para o re(pensar) } \\
\text { das práticas dos professores, } \\
\text { também para o período pós- } \\
\text { pandemia. }\end{array}$ \\
\hline SANTOS, 2020 & $\begin{array}{l}\text { Educação escolar } \\
\text { no contexto de } \\
\text { pandemia: } \\
\text { algumas } \\
\text { reflexões. }\end{array}$ & $\begin{array}{l}\text { Gestão e } \\
\text { Tecnologia } \\
\text { Faculdade } \\
\text { Delta }\end{array}$ & $\begin{array}{l}\text { Refletir sobre a } \\
\text { educação } \\
\text { escolar no } \\
\text { contexto de } \\
\text { pandemia. }\end{array}$ & $\begin{array}{l}\text { Enfatiza que o discurso } \\
\text { apressado de revolução na } \\
\text { educação pós-crise da } \\
\text { Covid-19 é incoerente do } \\
\text { ponto de vista histórico e } \\
\text { teórico. }\end{array}$ \\
\hline $\begin{array}{l}\text { ALMEIDA, } \\
\text { LEITE, } \\
\text { FERREIRA, } \\
\text { FARIAS, 2020 }\end{array}$ & $\begin{array}{l}\text { Ensino remoto e } \\
\text { tecnologia: uma } \\
\text { nova postura } \\
\text { docente na } \\
\text { educação pós- } \\
\text { pandemia. }\end{array}$ & CONEDU & $\begin{array}{l}\text { Discutir os } \\
\text { novos } \\
\text { contextos e } \\
\text { posturas } \\
\text { docentes diante } \\
\text { do ensino } \\
\text { remoto. }\end{array}$ & $\begin{array}{l}\text { O ensino remoto, apesar de } \\
\text { desafiador, poderá deixar } \\
\text { mudanças positivas na nossa } \\
\text { educação. }\end{array}$ \\
\hline $\begin{array}{c}\text { TEIXEIRA, } \\
\text { NASCIMENTO, } \\
2021\end{array}$ & $\begin{array}{c}\text { Ensino remoto: } \\
\text { ouso do Google } \\
\text { Meet na } \\
\text { pandemia da } \\
\text { COVID-19. } \\
\end{array}$ & BOCA & $\begin{array}{l}\text { Analisar o } \\
\text { potencial do } \\
\text { Google Meet } \\
\text { como }\end{array}$ & $\begin{array}{c}\text { É fundamental que docentes } \\
\text { e alunos adquiram a cultura } \\
\text { do ensino remoto ou da aula } \\
\text { online, no qual os alunos }\end{array}$ \\
\hline
\end{tabular}




\begin{tabular}{|c|c|c|c|c|}
\hline & & & $\begin{array}{l}\text { ferramenta } \\
\text { para ensinar e } \\
\text { aprender. }\end{array}$ & $\begin{array}{c}\text { necessitam ter disciplina } \\
\text { para poder ter bons } \\
\text { rendimentos. }\end{array}$ \\
\hline MACEDO, 2021 & $\begin{array}{c}\text { Direito ou } \\
\text { privilégio? } \\
\text { Desigualdades } \\
\text { digitais, } \\
\text { pandemia e os } \\
\text { desafios de uma } \\
\text { escola pública. }\end{array}$ & $\begin{array}{l}\text { Estudos } \\
\text { Históricos }\end{array}$ & $\begin{array}{l}\text { Discutir alguns } \\
\text { dos impactos } \\
\text { na educação } \\
\text { durante a } \\
\text { pandemia de } \\
\text { COVID-19 no } \\
\text { Brasil em 2020, } \\
\text { focalizando a } \\
\text { questão do } \\
\text { acesso às } \\
\text { atividades } \\
\text { online por } \\
\text { estudantes do } \\
\text { ensino básico. }\end{array}$ & $\begin{array}{l}\text { Insuficiência de políticas } \\
\text { públicas educacionais no } \\
\text { período pandêmico, que não } \\
\text { garantiram a conectividade } \\
\text { e o direito à educação no } \\
\text { país em meio à crise. }\end{array}$ \\
\hline $\begin{array}{c}\text { CASTIONI, } \\
\text { MELO, } \\
\text { NASCIMENTO, } \\
\text { RAMOS, 2021 }\end{array}$ & $\begin{array}{c}\text { Universidades } \\
\text { federais na } \\
\text { pandemia da } \\
\text { Covid-19: acesso } \\
\text { discente à } \\
\text { internet e ensino } \\
\text { remoto } \\
\text { emergencial. }\end{array}$ & Ensaio & $\begin{array}{c}\text { Analisar as } \\
\text { respostas } \\
\text { imediatas das } \\
\text { universidades } \\
\text { quando as } \\
\text { atividades } \\
\text { presenciais } \\
\text { precisaram ser } \\
\text { suspensas. }\end{array}$ & $\begin{array}{c}\text { O ensino remoto } \\
\text { emergencial surge como } \\
\text { caminho imediato em meio } \\
\text { à pandemia, mas são as } \\
\text { metodologias de ensino } \\
\text { híbrido que tendem a se } \\
\text { consolidar no mundo pós- } \\
\text { pandemia. }\end{array}$ \\
\hline
\end{tabular}

Fonte: (SCIELO, GOOGLE ACADÊMICO, CAPES E LILACS, 2021).

$\mathrm{Na}$ imagem 2 da tabela a cima, evidencia-se que os artigos selecionados ressaltam a importância do ensino remoto no período pandêmico e os métodos emergentes possuem implicações, assim como também possibilidades para uma educação acessível e de qualidade.

Nota-se que o reconhecimento da educação digital em rede se tornou presente no cotidiano de alunos e professores, nesse viés, a promoção de práticas pedagógicas construtivistas são de extrema necessidade para que a aprendizagem colaborativa aconteça e o conhecimento coletivo possa ser expandido. Pois, os processos de inovação ocorrem a partir da ação e empenho dos diferentes indivíduos que atuam na comunidade (MOREIRA, HENRIQUES, BARROS, 2020).

Segundo os autores, Valente et al (2020), as práticas emergentes de ensino e aprendizagem remota desencadearam inúmeros desafios, como por exemplo: o aumento de demandas de suporte tecnológico dos alunos para a realização de 
atividades, adaptações curriculares, formação de docentes para as práticas com os novos recursos digitais, ausência de equipamentos digitais e entre outras problemáticas.

Destaca-se ainda, que a pandemia não trouxe apenas desafios e implicações no âmbito educacional, mas possibilitou também o surgimento de novas ferramentas, mídias e tecnologias de ambientes virtuais de grande extensão. Além de promover metodologias ativas que impulsionam a autonomia dos alunos para buscarem conhecimento e não serem passivos no processo de ensino e aprendizagem (OLIVEIRA, FERNANDES, ANDRADE, 2020). Ademais, como disse o patrono da educação brasileira, Paulo Freire, o homem não se constitui no silêncio ou no comodismo, mas sim com o trabalho, com as palavras e principalmente na ação-reflexão.

O uso de recursos e ferramentas tecnológicas são de suma importância no contexto de ensino remoto e alguns merecem destaque, como: aplicativos de vídeo conferência, mapas mentais, jogos didáticos, plataformas educacionais e testes. No entanto, a escolha da melhor e mais acessível ferramenta digital é responsabilidade de escolha do professor, pois cabe a cada docente decidir qual o método tecnológico é mais adequado com o seu conteúdo em detrimento do processo de ensinoaprendizagem (ALMEIDA et al, 2020).

É importante ressaltar que a pandemia da COVID-19 evidenciou desigualdades que já existiam no Brasil, inclusive as digitais, pois até mesmo com a popularização da internet e dos smartphones o acesso não é para todos os cidadãos brasileiros devido a fatores de rendas e estratificação social. Nesse ínterim, o letramento digital também se mostra desigual por diferentes variáveis como idade, capital cultural e tipo de profissão (MACEDO, 2021).

Por fim, torna-se evidente as implicações que surgiram com a pandemia da COVID-19, em que ações foram suspensas no meio acadêmico e as atividades tiveram que ser repensadas e direcionadas para o método de ensino remoto, o que também provocou avanços no âmbito da formação acadêmica e na cidadania digital (CASTIONI et al, 2021). 


\section{CONSIDERAÇÕES FINAIS}

A partir de análises dos artigos supracitados foi possível alcançar o objetivo geral proposto pela presente revisão sistemática. Ressalta-se que o ensino remoto possibilitou implicações e desafios para as práticas educativas, além de avanços e novas possibilidades no processo de ensino- aprendizagem no contexto pandêmico.

Portanto, o ensino remoto permitiu mudanças positivas para as práticas educacionais, assim como evidenciou as implicações relacionadas à insuficiência de políticas públicas que não garante o acesso democrático de conexão e ferramentas digitais, além do direito primordial a educação.

Diante disso, é necessário estimular pesquisas de campo para fazer levantamentos das implicações e dificuldades do ensino remoto, além de análises das possibilidades para a promoção de novas práticas pedagógicas no contexto da educação digital. Nesse ínterim, são necessárias intervenções e estratégias coletivas para que todos os indivíduos participem de modo ativo no processo de ensino remoto e a aprendizagem digital se torne democrática e de qualidade no Brasil. 


\section{REFERÊNCIAS}

ALMEIDA, Evania Guedes de et al. Ensino remoto e tecnologia: uma nova postura docente na educação pós-pandemia. CONEDU, Maceió, 2020. Disponível em: https://editorarealize.com.br/artigo/visualizar/68528. Acesso em: 14/07/2021.

CASTIONI, Remi et al. Universidades federais na pandemia da Covid-19: acesso discente à internet e ensino remoto emergencial. Ensaio: aval. pol. públ. Educ., Rio de Janeiro, V.29, №111, p. 399-419, abr./jun. 2021. Disponível em: https://doi.org/10.1590/S0104-40362021002903108. Acesso em: 02/08/2021.

ERCOLE, Flávia Falci; MELO, Laís Samara de; ALCOFORADO, Carla Lúcia Goulart Constant. Revisão integrativa versus revisão sistemática. Revista Mineira de Enfermagem. Volume 18.1, 2014. Disponível em: http://www.dx.doi.org/10.5935/1415-2762.20140001. Acesso em: 08/07/2021.

HODGES, Charles et al. Diferenças entre o aprendizado online e o ensino remoto de emergência. Revista Escribo. V.2. 2020. Disponível em: https://escribo.com/revista/index.php/escola/article/view/17/16. Acesso em: 13/10/2021.

MACEDO, Renata Mourão. Direito ou privilégio? Desigualdades digitais, pandemia e os desafios de uma escola pública. Estudos Históricos, Rio de Janeiro, V.34, № 73, p.262-280, Maio-Agosto 2021. Disponível em: https://doi.org/10.1590/S2178149420210203. Acesso em: 25/07/2021.

MOREIRA, José António Marques; HENRIQUES, Susana; BARROS, Daniela. Transitando de um ensino remoto emergencial para uma educação digital em rede, em tempos de pandemia. Dialogia, São Paulo, n. 34, p. 351-364, jan./abr. 2020. Disponível em: https://doi.org/10.5585/Dialogia.N34.17123. Acesso em: 05/ 07/2021.

MUNCK, Luciano. BORGES, Monica. Aprendizagem, desenvolvimento de competências e reflexões sobre o aprender: relato de experiência utilizando aprendizado mais profundo e metodologias ativas. Revista Alcance, vol. 27, núm. 1, pp. 4-17, Universidade do Vale do Itajaí, Brasil, 2020. Disponível em: https://www.redalyc.org/jatsRepo/4777/477762769003/477762769003.pdf. Acesso em: $13 / 10 / 2021$.

OLIVEIRA, Jussara de Fátima Alves Campos; FERNANDES, Juliana Cristina da Costa; ANDRADE, Elisângela Ladeira de Moura. Educação no contexto da pandemia da Covid19: adversidades e possibilidades. Itinerarius Reflectionis, V.16, №1, 2020. Disponível em: https://www.revistas.ufg.br/rir/article/view/65332. Acesso em: 10/07/2021.

SANTANA, Camila Lima Santana e; SALES, Kathia Marise Borges. Aula em casa: educação, tecnologias digitais e pandemia COVID-19. Interfaces Científicas, Aracaju, №1, V.10, p.75-92, 2020. Disponível em: 10.17564/2316-3828.2020v10n1p75-92. Acesso em: 10/07/2021. 
SANTOS, Claitonei de Siqueira. Educação escolar no contexto de pandemia: algumas reflexões. Gestão \& Tecnologia, V.1, ed. 30, Jan/Jun 2020. Disponível em: http://www.faculdadedelta.edu.br/revistas3/index.php/gt/article/view/52. Acesso em: $14 / 07 / 2021$.

TEIXEIRA, Daiara Antonia de Oliveira; NASCIMENTO, Francisleile Lima. Ensino remoto: o uso do Google Meet na pandemia da COVID-19. BOCA, Boa Vista, V.7, № 19, 2021. Disponível em: http://www.ioles.com.br/boca. Acesso em: 18/07/2021.

VALENTE, Geilsa Soraia Cavalcanti et al. $\mathbf{O}$ ensino remoto frente às exigências do contexto de pandemia: Reflexões sobre a prática docente. Research, Society and Development, v. 9, n. 9, 2020. Disponível em: http://dx.doi.org/10.33448/rsdv9i9.8153. Acesso em: 08/07/2021.

VERASZTO, Stéfano Vizconde et al. Tecnologia: buscando uma definição para o conceito. PRISMA. COM, 2009. № 8, 2009. Disponível em: https://ojs.letras.up.pt/index.php/prismacom/article/view/2065/1901. Acesso em: 05/ $07 / 2021$. 